\title{
QUALIDADE E SEGURANÇA AGROALIMENTAR: A INFLUÊNCIA DO TRANSPORTE NA QUALIDADE DO PEIXE
}

\author{
Bruna Siqueira LOZANO ${ }^{1}$ \\ Rafael FOREST ${ }^{2}$ \\ Fernando WOSGRAU ${ }^{3}$ \\ Marlene FOREST ${ }^{4}$ \\ Erlaine BINOTTO ${ }^{5}$
}

1 Bacharel em Ciências Contábeis. Mestranda do Programa de Pós Graduação em Agronegócios PPGAGRONEGÓCIOS da Universidade Federal da Grande Dourados - UFGD. E-mail: brunalozano1 @ hotmail.com

${ }^{2}$ Bacharel em Administração de Empresas habilitação em Comércio Exterior. Mestrando do Programa de Pós Graduação em Agronegócios - PPGAGRONEGÓCIOS da Universidade Federal da Grande Dourados - UFGD. E-mail: rafael_forest@hotmail.com

${ }^{3}$ Bacharel em Administração de Empresas habilitação em Comércio Exterior. Mestrando do Programa de Pós Graduação em Agronegócios - PPGAGRONEGÓCIOS da Universidade Federal da Grande Dourados - UFGD. E-mail: wosgrau@yahoo.com.br

${ }^{4}$ Bacharel em Administração de Empresas habilitação em Comércio Exterior. Mestranda do Programa de Pós Graduação em Agronegócios - PPGAGRONEGÓCIOS da Universidade Federal da Grande Dourados - UFGD. E-mail: forestnew@bol.com.br

${ }^{5}$ Doutora em Agronegócios pela Universidade Federal do Rio Grande do Sul - UFRGS. Professora Adjunta II da Universidade Federal da Grande Dourados e Coordenadora do Programa de Pós Graduação em Agronegócios PPGAGRONEGÓCIOS da Universidade Federal da Grande Dourados - UFGD. E-mail: erlainebinotto@ufgd.edu.br

\section{Recebido em: 17/05/2014 - Aprovado em: 30/06/2014 - Disponibilizado em: 30/07/2014}

Resumo: Requisitos para assegurar a qualidade dos produtos durante a expedição e distribuição são tão importantes quanto qualquer outro critério de especificação do produto. O consumidor está cada vez mais atento e exigente com a qualidade dos alimentos que deseja consumir. O peixe é um alimento proteico de fácil deterioração, práticas adequadas e procedimentos corretos no manuseio, transporte e embalagem do pescado, são necessários para garantia de um produto seguro e com qualidade. Diante disso, o presente artigo tem como objetivo, analisar a influência do transporte na qualidade do peixe, na perspectiva da qualidade e segurança agroalimentar. Para tanto, a pesquisa caracterizou-se por um estudo descritivo de caráter qualitativo, por meio da pesquisa bibliográfica por meio de dados secundários. As análises indicam que apesar do pescado estar entre as proteínas animal de maior consumo no mundo, esta ainda não é a realidade no Brasil. Das mais variadas causas, estão às razões culturais e socioeconômicas, a falta de políticas públicas voltadas ao setor, à ausência de estabelecimentos comerciais especializados na venda de pescado e falta de qualidade dos produtos, objeto do presente estudo. Portanto, conclui-se que o transporte influencia na qualidade do pescado, é uma etapa tão importante quanto qualquer outra e por isso deve ser feita atendendo técnicas e procedimentos corretos.

Palavras-chave: Peixe, Qualidade, Segurança, Transporte.

\section{QUALITY AND SAFETY AGROALIMENTAR: THE INFLUENCE OF TRANSPORT IN THE QUALITY OF FISH}

\begin{abstract}
Requirements to ensure the quality of products during shipping and distribution are as important as any other criterion of a product specification. Consumers are increasingly aware and demanding with the quality of food they want to consume. Fish is a protein food spoilage easy, appropriate practice and proper procedures in handling, packing and transport of fish are needed to guarantee a safe and quality product. Therefore, this article aims to analyze the influence of transport on quality of the fish, from the perspective of quality and agrifood safety. Therefore, the research was characterized by a descriptive qualitative study, through literature through secondary data. The analyzes indicate that despite being caught between Animal proteins largest consumer in the world, this is not yet a reality in Brazil. The most varied causes are the cultural and socioeconomic reasons, the lack of public policies aimed at the sector, the lack of specialized shops selling fish and lack of quality of the products, the object of this study. Therefore, it is concluded that the transport influences the quality of the fish, is a step as important as any other and should therefore be given proper techniques and procedures.
\end{abstract}

Key words: Fish, Quality, Safety, Transportation. 


\section{INTRODUÇÃO}

A aquicultura é uma atividade diversificada, em crescente ascensão no Brasil. A aquicultura abrange uma vasta gama de espécies, sistemas e práticas, cujo significado, é o cultivo de organismos, em que o ciclo de vida em condições naturais se dá total ou parcialmente em meio aquático (MPA, 2014). O aumento populacional, a urbanização, e a crescente preocupação com hábitos alimentares saudáveis nos países desenvolvidos e elevação do poder de compra nos países em desenvolvimento são fatores que vêm contribuindo para o aumento da demanda mundial por pescados (SIDONIO et al. 2012).

O país possui um enorme potencial para a produção de pescado, com uma das maiores reservas de água doce do mundo, com cerca de 8,2 bilhões de metros cúbicos de água em rios, lagos, açudes e represas, além da extensa faixa litorânea, sua produção anual de pescado gira em torno de 1,5 milhão de toneladas, mesmo que ainda pequena em relação ao seu potencial (BRASIL, 2014). Todavia, o aproveitamento dos recursos para a produção aquícola ainda está muito abaixo do seu potencial.

O pescado está entre as proteínas animal, com maior produção e consumo mundial. O Brasil apesar de dispor de condições naturais muito favoráveis à produção de pescados possui uma produção e consumo inferior à média global. O peixe é um alimento proteico de fácil deterioração, exigindo cuidados e técnicas adequadas de manuseio, transporte e armazenagem, para assegurar que chegue com qualidade até o consumidor final.

Há uma mudança de comportamento por parte do consumidor, na busca por segurança e garantia de consumir alimentos com qualidade. Os requisitos para assegurar a qualidade dos produtos durante a expedição e distribuição são tão importantes quanto qualquer outro critério de especificação do produto, devendo ser controlados e gerenciados de modo tão detalhado quanto nas demais etapas do processo de manufatura de alimentos (BORRÁS; TOLEDO, 2006).

Sobre a qualidade do pescado, Batista et al. (2004) afirma que o manuseio, transporte e a conservação incorretamente aplicados durante da captura e comercialização representam os principais problemas na manutenção da qualidade do pescado, instigando o surgimento de novas pesquisas.

Se há a percepção de que o consumidor está mudando seu comportamento, no sentido de maior exigência na qualidade do que consome, é preciso compreender os fatores externos que podem pôr em risco e até mesmo comprometer a segurança em consumir o pescado.

Diante disso, o presente trabalho possui como principal objetivo, analisar a influência do transporte na qualidade do 
peixe, dentro do contexto da segurança alimentar.

\section{METODOLOGIA}

Esse estudo caracterizou-se como descritivo de caráter qualitativo, por meio da pesquisa bibliográfica.

A título de conhecimento, o termo pescado foi utilizado no estudo, para tratar animais aquáticos, sejam eles provenientes da aquicultura ou da pesca.

Para que a comparação dos resultados de consumo, produção e exportação pudesse ser feita, foi necessário utilizar dados de 2009, uma vez que este se encontrou disponível em todas as fontes pesquisadas: Organização das Nações Unidas para Alimentação e Agricultura (FAO), Instituto Brasileiro de Geografia e Estatística (IBGE), Ministério da Pesca e Aquicultura (MPA) e Departamento de Agricultura dos Estados Unidos (USDA).

\section{RESULTADOS E DISCUSSÃO}

Os resultados e discussão dão ênfase nas definições de qualidade e segurança agroalimentar, em seguida sobre a aquicultura, produção, consumo e exportação do pescado no âmbito nacional e internacional. Posteriormente, discorre sobre o transporte do peixe, fazendo uma análise sobre sua influência na qualidade deste produto.

\section{Qualidade e Segurança Agroalimentar}

A diversidade de produtos agroalimentares e os problemas de segurança alimentar conduzem à incerteza sobre a qualidade dos produtos (STAUDT et al. 2009). Segundo Forsman e Paananem (2002), há um interesse cada vez maior por parte dos consumidores, pela qualidade e segurança dos alimentos.

O conceito de segurança alimentar, diz respeito ao acesso da população aos alimentos, sua disponibilidade, e a oferta de alimentos para toda população que pode depender da produção, importação, sistemas de armazenamento e distribuição, o acesso físico e econômico aos alimentos, ou seja, a capacidade de obter alimentos em quantidade (IBGE, 2010).

A definição de segurança agroalimentar para Belik (2003), é estabelecida por limites e prioridades para as políticas sociais, esse conceito leva em conta três aspectos principais: quantidade, qualidade e regularidade no acesso aos alimentos. Em sentido semelhante FAO (2014), entende que segurança alimentar é a situação que existe quando todas as pessoas, em todos os momentos, têm acesso físico, social e econômico a alimentos suficientes, seguros e nutritivos que atendam suas necessidades dietéticas e preferências alimentares para uma vida ativa e saudável.

O conceito de segurança alimentar pode ser visto por diferentes enfoques, entretanto, neste estudo será visto sob o 
enfoque de alimentos seguros, alimentos que não apresentam risco à saúde do consumidor, ou seja, alimentos isentos de contaminantes físicos, químicos e biológicos.

Os conceitos de qualidade de produtos agroalimentares e de segurança do alimento são considerados como distintos e indissociáveis ao longo da cadeia agroalimentar (BORRÁS; TOLEDO, 2006). Muitas vezes, como relata Simões (2011) esses conceitos são confundidos ou tratados como similares ou mesmo equivalentes, sendo, no entanto, conceitos diferentes. A preocupação com a qualidade e seu conceito sofreu adaptações com o desenvolvimento tecnológico e a necessidade crescente de segurança (PERETTI; ARAÚJO, 2010).

Para Spers (2000) a qualidade está relacionada com o alimento de qualidade, aquele que de maneira consistente, atende às necessidades do consumidor em termos de conveniência, de propriedades funcionais, nutritivas, de higiene e segurança, e que respeite a legislação pertinente e informa o consumidor quanto aos cuidados, modos de preservação, preparo e ingestão. Enquanto a segurança do alimento refere-se àquele que não apresenta um risco significativo para saúde.

Parâmetros de qualidade, de
segurança do alimento e exigências de
qualidade são condições mínimas que um
produto agroalimentar deve obedecer,
algumas dessas exigências são ocultas
(intrínseca), outras se referem à importância

dos padrões de qualidade de apresentação, para a decisão de compra do produto (TOLEDO, 2001). Esses parâmetros de qualidade são entendidos por Spers (2000, p. 15), como sendo "a garantia de o consumidor adquirir um alimento com atributos de qualidade que sejam do seu interesse, entre os quais destacam-se os atributos ligados a sua saúde e segurança".

A segurança do alimento, é a garantia em se consumir um alimento isento de resíduos que prejudiquem ou causem danos à saúde (FAO, 2014). O conceito de qualidade para Borrás e Toledo (2006), parte da ideia de que assegurar a qualidade dos produtos agroalimentares passa, necessariamente, pela garantia de que os processos de fabricação e armazenagem estejam de acordo com padrões fitossanitários, rigorosos e capazes de detectar possíveis falhas no processamento, embalagem e transporte que sejam fontes em potencial de agentes contaminantes e que possam contribuir para a contaminação do alimento e posterior risco à saúde de seu consumidor final.

Corroborando, Toledo compreende que a qualidade de produto pode ser vista como sendo a propriedade síntese de múltiplos atributos do produto que determinam o grau de satisfação do cliente, envolvendo também a embalagem, orientação para uso, imagem, serviços pós venda e outras características associadas ao produto. 
Forsman e Paananem (2002)

discorrem que atributos como denominação de origem, rastreabilidade e transparência nos processos produtivos, tem ganhado espaço nos últimos anos, atributos esses que passam segurança ao consumidor quanto à qualidade do produto.

A crescente preocupação com qualidade e segurança dos alimentos é a base para a implantação de um programa de qualidade em toda a cadeia, pois através dela as preferências e a satisfação do consumidor seriam contempladas.

\section{Aquicultura}

O peixe é uma importante fonte de alimentos, contribui para a segurança alimentar em numerosas regiões do mundo, sendo que mais de $75 \%$ da produção mundial de peixe é destinada ao consumo humano (FAO, 2014). Os peixes contém alto valor nutritivo, possuem elevados teores de vitamina A e $\mathrm{D}$, gordura insaturada, proteína de excelente valor biológico, além de ser fonte de cálcio e fósforo (EMBRAPA, 2014).

A importância dessa atividade é verificada na Tabela 1 que traz os valores de produção, exportação e consumo nos paísesmembros da ONU- Organização das Nações Unidas.

Tabela 1 - Proteínas travessão mundo - 2009

\begin{tabular}{lccc}
\hline & Produção & Exportação & Consumo \\
& (mil ton) & (mil ton) $* *$ & (mil ton) \\
\hline Pescados* & 145.100 & 32.348 & 116.960
\end{tabular}

\begin{tabular}{llll} 
Suínos & 100.399 & 12.066 & 100.268 \\
Aves & 72.293 & 10.733 & 71.860 \\
Bovinos & 57.027 & 9.607 & 56.116 \\
$\begin{array}{l}\text { Caprinos e } \\
\text { ovinos }\end{array}$ & 13.236 & 1.007 & 13.139 \\
\hline
\end{tabular}

Fontes: FAO, MPA, USDA (2014). Elaboração: Adaptado pelo autor.

* Os dados não incluem a produção de plantas aquáticas.

**Os dados da FAO referem-se ao total exportado pelos países-membros da ONU.

Constata-se através da análise da Tabela 1, que o pescado é a proteína animal de maior produção e consumo pelos paísesmembros da ONU. Em 2009, o consumo de pescado foi de cerca de 116.960 mil toneladas, o que daria de acordo com Sidonio et al. (2012), um valor superior a $17 \mathrm{~kg}$ por habitante. Outro aspecto importante que o autor destaca, é que a demanda mundial por pescados vem crescendo em decorrência do aumento populacional e da busca por alimentos mais saudáveis.

Os valores de produção, consumo e exportação de pescado no Brasil são apresentados na Tabela 2.

Tabela 2 - Proteínas travessão Brasil - 2009

\begin{tabular}{lccc}
\hline & $\begin{array}{c}\text { Produção } \\
\text { (mil ton) }\end{array}$ & $\begin{array}{c}\text { Exportação } \\
* * \\
\text { (mil ton) }\end{array}$ & $\begin{array}{c}\text { Consumo } \\
\text { (mil ton) }\end{array}$ \\
\hline Aves & 11.023 & $3.265,000$ & 8.023 \\
Bovinos & 9.180 & $1.422,000$ & 7.410 \\
Suínos & 3.130 & 643,000 & 2.423 \\
Pescados & 1.241 & 30,000 & 1.723 \\
$*$ & & & \\
Caprinos & 110 & 0,048 & 117 \\
e ovinos & & & \\
\hline
\end{tabular}

Fonte: FAO, MPA, USDA (2014). Elaboração: Adaptado pelo autor.

Comparando-se os dados dos paísesmembros da ONU com os dados do Brasil, observa-se, que a maior produção e consumo 
no Brasil são de carnes de frango seguida da bovina.

Nota-se que a média de consumo de pescado per capita brasileira foi inferior ao da média global. E mesmo com o consumo abaixo da média, a produção interna somada as exportações não seriam capaz de suprir essa demanda interna por pescado, efetivamente, a produção de pescado menos as exportações deixam no mercado interno $1.221 \mathrm{t}$ de peixes, com a demanda de $1.723 \mathrm{t}$, o déficit de pescado no Brasil no ano de 2009 foi de $512 \mathrm{t}$.

Entretanto, o Brasil tem condições de aumentar a produção de peixe, segundo o Ministério da Pesca e da Aquicultura (MPA, 2014), o Brasil é um dos poucos países que tem condições de atender à crescente demanda mundial por produtos de origem pesqueira, sobretudo por meio da aquicultura. Mesmo dispondo de condições favoráveis, o Brasil não ocupa posição de destaque no mercado mundial de pescados. Sobre os desafios para o desenvolvimento da aquicultura brasileira, Sidonio et al. (2012), explica que a aquicultura encontra-se pouco estruturada no Brasil, haja vista, que há dificuldades na obtenção de licenças, carência de assistência técnica, manejo inadequado, falta de padronização, insuficiência de pacotes tecnológicos e grande necessidade de capital de giro. Outros fatores são apontados pela Empresa Brasileira de Pesquisa Agropecuária Embrapa (2014), ressalva que, o consumo de pescado brasileiro ainda é baixo, causado dentre outros fatores por razões culturais e socioeconômicas, pela falta de políticas públicas voltadas ao setor, pela ausência de estabelecimentos comerciais especializados na venda de pescado e falta de qualidade dos produtos encontrados em feiras livres e entrepostos.

A Embrapa (2014) alerta que o pescado é um alimento nutritivo, entretanto, pode ser contaminado por patogênicos no ambiente ou se for manuseado de forma inadequada. Por exemplo, os endoparasitos, as biotoxinas, poluentes químicos e metais tóxicos, alguns desses contaminantes podem causar uma pequena e passageira intoxicação alimentar, enquanto outras substâncias (como as biotoxinas) podem provocar um problema neurológico grave ao consumo humano, se manuseado, transportado e Simões (2011), afirma que, para que seja considerado perigoso, o pescado deve apresentar potencial para causar efeitos adversos na saúde do consumidor, seja por meio de agentes biológicos, químicos ou físicos existentes no alimento. Esses vários tipos de perigos podem já estar presentes nos alimentos no momento da sua aquisição, nas embalagens alimentares ou podem ser adquiridos em qualquer fase da preparação.

Algumas medidas podem minimizar a contaminação do pescado, ou mesmo impedir a veiculação de certas doenças, diminuindo o risco de ingestão de um produto contendo algum tipo de patógeno ou 
toxina, ou seja, medidas essas se forem tomadas, aumentam a qualidade do peixe e garantem a segurança desse produto. (USDA, 2014).

É crescente a preocupação com a qualidade dos produtos alimentícios, em especial no que se refere à sua segurança, devido ao desenvolvimento de novas tecnologias e à credibilidade dos órgãos responsáveis pela saúde pública (PERETTI; ARAÚJO, 2010). Sem mencionar também, que alimentos seguros e com qualidade é uma questão de saúde pública.

Como demonstrado a importância de se consumir um peixe de qualidade, o tópico seguinte trata do transporte do peixe e a relação desse processo com a qualidade do pescado.

\section{Transporte do peixe e sua influência na qualidade do produto}

O peixe, por sua natureza, é um dos alimentos proteicos considerados mais fáceis de sofrer deterioração, inúmeros microrganismos presentes nas águas, bem como a microbiota natural do pescado, localizada principalmente nos intestinos, guelras e limo superficial (GOMES, 2006).

O manuseio, transporte e a conservação incorretamente aplicada durante a captura e comercialização representam os principais problemas para manter a qualidade do pescado (BATISTA, 2004).

O transporte de peixes, vivos ou já abatidos, exige cuidados e manuseios adequados, para tanto, se faz necessário à utilização de procedimentos básicos e práticas adequadas, para que não se perca a qualidade no produto. A manipulação do pescado fresco, o transporte, e a armazenagem durante $\mathrm{o}$ período compreendido entre captura e processo, são cruciais para a qualidade do produto final (MACHADO, 1984). Kubitza (1997) relata que o transporte de peixes vivos é uma rotina dentro e fora das granjas de piscicultura, representando um considerável custo e risco aos piscicultores, transportadores de peixes e proprietários de pesqueiros.

O manuseio e o transporte de peixes possuem a capacidade de afetar as características do pescado, quando estes se apresentam em estresse, ocorrem alterações nas características sensoriais, químicas e microbiológicas do peixe (KODAIRA, 1994). O tempo de transporte, a temperatura da água, o tamanho dos peixes, o jejum antes do transporte, o uso de anestésicos e a espécie de peixe, são os principais fatores que afetam a carga de peixes, possivelmente transportados em tanques ou em sacos plásticos (KUBITZA, 1997).

Assim, para que se tenha um produto de qualidade, é necessária uma série de cuidados, desde a sua captura e armazenamento a bordo até seu transporte e processamento (GALVÃO, 2014).

Segundo Gomes (2006), problemas no transporte de alimentos proteicos de origem animal, especificamente de produtos pesqueiros, cuja perecibilidade se apresenta 
como um processo natural, que se inicia tão logo quando o peixe é capturado e morto, assume riscos e custos altos, que exigem uma pronta intervenção do homem. Entretanto, de acordo com Kubitza (1997), o uso de procedimentos básicos no transporte de peixes e a utilização de estratégias adequadas de transporte permite minimizar tais riscos e custos.

Os requisitos para assegurar a qualidade dos produtos durante a expedição e distribuição são tão importantes quanto qualquer outro critério de especificação do produto, devendo ser controlados e gerenciados de modo tão detalhado quanto nas demais etapas do processo de manufatura de alimentos (BORRÁS; TOLEDO, 2006).

O transporte do peixe é uma importante etapa do processo, entretanto, para que os produtos permaneçam com a garantia de qualidade e de alimento seguro, é imprescindível que todas as etapas da cadeia produtiva do peixe estejam adequadamente organizadas, bem como o processo de transporte seja feito de maneira correta, obedecendo a padrões de higiene e manuseio, pois o mesmo pode comprometer toda a cadeia pesqueira, colocando em risco a qualidade do pescado e a garantia de um alimento seguro a saúde de quem o consome. Ou seja, o transporte possui a capacidade de influenciar na qualidade do peixe.

\section{CONSIDERAÇÕES FINAIS}

O presente artigo teve como objetivo, analisar a influência do transporte na qualidade do peixe. Através da contextualização dos conceitos de segurança e qualidade agroalimentar, fica evidente a importância em consumir alimentos seguros, saudáveis e com qualidade. Para ser considerado um alimento seguro, é necessário que contaminantes físicos, químicos e biológicos estejam ausentes no produto.

Todavia, para que isso ocorra de fato, e que a qualidade do alimento esteja assegurada é necessário que tenha uma implantação de um programa de qualidade em toda a cadeia. A maneira com a qual os peixes são transportados deve ser vista, como uma importante etapa no processo, uma vez que, por ser um produto de origem animal de fácil deterioração, o transporte deve ser feito adequadamente, para que se não coloque em risco a qualidade do produto.

Apesar de o pescado estar entre as proteínas animal de maior consumo mundial, esta ainda não é a realidade no Brasil. Constatou-se com este estudo, que das mais variadas causas, estão às razões culturais e socioeconômicas, a falta de políticas públicas voltadas ao setor produtivo, dificuldades na obtenção de licenças, carência de assistência técnica, manejo inadequado, falta de padronização, insuficiência de pacotes tecnológicos, grande 
necessidade de capital de giro, a ausência de estabelecimentos comerciais especializados na venda de pescado e falta de qualidade dos produtos.

$$
\text { Portanto, constata-se que o }
$$
transporte influência na qualidade do pescado, sendo esta, uma etapa tão importante quanto qualquer outra e por isso deve ser feita atendendo técnicas e procedimentos corretos. Outro aspecto importante que deve ser evidenciado, é que a conscientização dos consumidores, talvez seja uma forma de pressionar os mercados a oferecer produtos de qualidade e seguros, pois a mudança de comportamento por parte do consumidor faz com que os mercados também procurem tal mudança, para atender as preferências e a satisfação do consumidor.

$$
\text { Com uma melhor estruturação do }
$$

setor, seria possível um aumento na produção e consequentemente no consumo do pescado brasileiro. Fiscalização sanitária e educação alimentar também poderiam contribuir para aumentar o consumo de peixes de forma ordenada e segura, e proporcionar mais saúde aos seus consumidores.

Este estudo teve como fator limitante, o acesso aos dados secundários atualizados, referente à produção, consumo, e exportação, cujos valores referem-se aos anos de 2009 e 2010. Haja vista que quanto mais atualizado e recentes tais dados, os resultados obtidos na análise da influência do transporte na qualidade do peixe, também seriam. Para estudos futuros, sugere-se um estudo completo da cadeia pesqueira, desde a pesca até o consumidor final.

\section{REFERÊNCIAS}

BATISTA, G. M. LESSI, E. KODAIRA, M. FALCÃO, P. D. T. Alterações bioquímicas post-mortem de matrinxã Bryconcephalus (Günther, 1869) procedente da piscicultura, mantido em gelo. Ciência e Tecnologia de Alimentos, 24(4), 573-581, 2004.

BELIK, W. Perspectivas para segurança alimentar e nutricional no Brasil. Saúde e Sociedade, v. 12, n. 1, p. 12-20, 2003.

BRASIL. Boletim estatístico da pesca e aquicultura. Ministério da Pesca e Aquicultura - MPA. Brasília, fevereiro de 2012.

BRASIL. Produção de pescado no País cresce incentivada por políticas de fomento. Disponível em: < http://www.brasil.gov.br/noticias/arquivos/20 13/03/28/producao-de-pescado-no-paiscresce>. Acesso em: 20 Mar. 2014.

BORRÁS, M. A. A. TOLEDO, J. C. de. Qualidade dos produtos agroalimentares: A importância da gestão da qualidade no agronegócio. In: ZUIN, L. F. S. QUEIROZ, T. M. [et al.]. Agronegócios: Gestão e inovação. São Paulo: Saraiva 2006, p. 189.

EMBRAPA. Empresa Brasileira de Pesquisa Agropecuária. A importância do manejo higiênico-sanitário na qualidade do pescado. Disponível em: < http://www.embrapa.br/imprensa/artigos/2009 /a-importancia-do-manejo-higienico-sanitariona-qualidade-do-pescado/\#>. Acesso em: 10 Mar. 2014.

FAO. Food and Agricultural Organization. Aquicultura brasileira. Disponível em: $<$ http://www.fao.org/docrep/field/003/ac562p/ AC562P03.htm\#ch3.1>. Acesso em: 19 Mar. 2014. 
FORSMAN, S. PAANANEM, J. Local Food Systems: Explorative Findings Finland. In: Colloque Syal "Systèmes Agroalimentaires Localisè": Produts, Enterprises EtDinamiques Locales. 16-18 October. Montpellier, France. 2002.

GALVÃO, J. A. Boas práticas de fabricação: da despesca ao beneficiamento do pescado. Disponível em:

$<\mathrm{ftp}$ //ftp.sp.gov.br/ftppesca/IIsimcope/oficina _juliana_galvao.pdf $>$. Acesso em: 18 Mar. 2014.

GIL, A. C. Como elaborar projetos de pesquisa. São Paulo: Atlas, 2002.

GOMES, L. M. Influência das condições de manuseio e conservação na qualidade do pescado, 2006.

IBGE. Instituto Brasileiro de Geografia e Estatística. Segurança alimentar 2004/2009. Ministério do Planejamento, Orçamento e Gestão. Pesquisa Nacional por Amostra de Domicílios - PNAD. Rio de Janeiro, 2010.

KODAIRA,M. Manejo del pescado de agua continentalesen condiciones de refrigeración. Suplemento. FAO Informe de Pesca, Roma, n. 476, p.104-128,1994.

KUBITZA, F. Projeto Pacu. Panorama da Aquicultura. Parte, v. 1, p. 20-26, 1997.

MACHADO, Z. L. Tecnologia de produtos pesqueiros: parâmetros, processos e produtos. Ministério do Interior. Superintendência do Desenvolvimento do Nordeste (SUDENE-DRN). Recife, 277p. 1984.

MPA. Ministério da Pesca e da Aquicultura.Aquicultura. Disponível em: $<$ http://www.mpa.gov.br/index.php/aquicultur ampa/informacoes/o-que-e>. Acesso em: 10 Mar. 2014.

PERETTI, R. A. P. ARAÚJO, W. M. C. Abrangência do requisito segurança em certificados de qualidade da cadeia produtiva de alimentos no Brasil.Gest. Prod., São Carlos, v. 17, n. 1, p. 35-49, 2010.
SIDONIO, L. CAVALCANTI, I. CAPANEMA, L. MORCH, R. MAGALHÃES, G. LIMA, J. MUNGIOLI, R. Panorama da aquicultura no Brasil: desafios e oportunidades. BNDES Setorial Agroindústria, n. 35, p. 421-463, 2012.

SIMÕES, M. A. F. Segurança alimentar nos processos de confecção a quente em restauração tradicional. Dissertação (Mestrado integrado em Medicina Veterinária) - Universidade Técnica de Lisboa, Portugal, 2011.

SPERS, E. E. Qualidade e segurança em alimentos. In: ZYLBERSTAJN, D. NEVES, M. F. (Org.). Economia e gestão dos negócios agroalimentares. São Paulo: Pioneira, 2000, p. 284.

STAUDT, N. P. SATO, G. S. SILVA, R. VARELA, C. CHALITA, M. A. N. Processo de certificação de qualidade para produtos agroalimentares: o selo produto São Paulo. Revista Informações Econômicas, São Paulo, v.39, n. 3, 2009.

TOLEDO, J. C. Gestão da qualidade na agroindústria. In: BATALHA, M. O. (Org.). Gestão agroindustrial, 2. Ed. São Paulo:

Atlas, 2001. v. 1, p.472.

USDA. United States Department of Agriculture. Food Safety. Disponível em: $<$ http://www.usda.gov/wps/portal/usda/usdah ome>. Acesso em 15 Mar. 2014. 